\title{
Occurrence and decay patterns of common wood-decay fungi in hazardous trees felled in the Helsinki City
}

\author{
By M. Terho ${ }^{1}$, J. Hantula and A.-M. Hallaksela \\ Finnish Forest Research Institute, Vantaa Research Unit, Box 18, FIN-01301 Vantaa, Finland. \\ ${ }^{1}$ E-mail: minna.terho@metla.fi (for correspondence)
}

\begin{abstract}
Summary
To improve the management of ageing urban trees, the role of wood-decay fungi as potential causes of stem breakage was investigated among hazardous trees removed in the Helsinki City area during 20012004. The study material comprised 194 trees, and included 76 Tilia spp. trees, 58 Betula spp. and 60 Acer spp. Thirteen species or genera of commonly occurring decay fungi were identified on the basis of fruiting bodies and pure cultures. The occurrence of the fungi was investigated in terms of frequency, visibility and as potential causes for stem breakage. Most hazardous fungi caused extensive horizontal decay in the stem; such fungi were Ganoderma lipsiense on Tilia and Acer, Phellinus igniarius on Acer, Inonotus obliquus and Cerrena unicolor on Betula and Kretzschmaria deusta on Acer, Tilia and Betula. Typically, Rigidoporus populinus was frequently present in weak fork formations on Acer trees. Agaric fungi (Pholiota, Armillaria, Pleurotus and Hypholoma) were frequently recorded but were of minor importance from the point of view of tree breakage hazard.
\end{abstract}

\section{Introduction}

Assessment of the hazard risk of old trees with high amenity and landscape values is an important aspect of arboriculture. Decay is a crucial factors increasing the risk. The decay process in a living tree is a complex chain of environmentally influenced events driven by stress, competition and disturbance (RAYNER and BodDy 1986). Many organisms are involved in the decomposition of wood but, in terms of risk assessment, fungi are the main cause of decreased mechanical strength in a tree. Because of the complexity of this issue, careful analyses of hazardous trees are necessary to produce guidelines for tree management in public areas including streets, parks, yards and cemeteries.

Assessment of tree health is primarily based on the 'status quo' condition of a tree, but an understanding of the dynamics of interactions is also required. Research has approached the subject from a variety of perspectives. Inventory studies have demonstrated which fungal species are common in urban environments (e.g. SEeHANn 1979; ErkKiLÄ and Niemelä 1986). Detailed studies have been carried out on host-pathogen interactions, either on the potential of the fungus to break the defensive mechanisms of the tree (e.g. Schwarze and Fink 1997; Schwarze and Baum 2000), or on the ability of the tree to form protective barriers to restrict the spread of decay (e.g. Shigo 1979; Shortle 1979; Pearce 1991; Baum and Schwarze 2002). Attention has also been directed to the degradation strategies of different fungi (Blanchette 1984; Blanchette et al. 1985; RAYNer and BoDDY 1988) as well as to the factors such as horizontal spread of decay that are crucial to breakage of a stem (MATTHECK and BRELOeR 1994). As a result, concepts of important fungal species, host-pathogen combinations and factors that should be noted when assessing the decay on urban trees are well developed. On the other hand, the range of 
perspectives in different studies makes it difficult to understand the importance of different fungal species in local management.

There are 150000-200000 park trees and over 25000 street trees in the city of Helsinki (RAIsio, 2004, personal communication), mostly in the genera Tilia, Betula and Acer. Inventories have shown that a large number of old park and street trees are in a rather poor condition, and tree care specialists must decide their future. In the present study, we wanted to investigate the role of the most frequently occurring decay fungi in those trees that had been removed as a result of risk assessments made by tree care professionals. The aim was, apart producing basic information on the wood-decay fungi common in urban trees of Helsinki, to produce information of value to tree care specialists.

\section{Material and methods}

\subsection{Tree material}

The 194 park and street trees investigated in this work were located in the central parks and streets of the Helsinki City area $\left(60^{\circ} 15^{\prime} \mathrm{N}, 25^{\circ} 00^{\prime} \mathrm{E}\right)$. Seventy-six trees were Tilia species (mostly $T . \times$ vulgaris Hayne and T. platyphyllos Scop.), 58 were Betula species (mostly B. pendula Roth and B. pubescens Ehrh.) and 60 were Acer species (mostly $A$. platanoides L.). The trees were considered either as hazardous or declining with lowered amenity value, and were felled during 2001-2004. Tree care specialists from the Helsinki City administration or private entrepreneurs assigned by the city examined the trees, and the Public Works Department of the City of Helsinki was responsible for decision-making and felling. The authors of the present study also investigated the trees before felling, and after felling analysed decay in the stems and identified the common decay-causing agents.

Potential hazard characteristics of the trees used in the present study were reported previously (Terho and Hallaksela 2005). Grouping of tree material was performed retrospectively by applying the Tree AZ Categories (Version 3.08 by Barrell Treecare: http://www.barrelltreecare.co.uk, accessed 5.11.2003). In the present paper, only trees with the potential hazard categories Z3 (dead, dying, diseased or declined trees), Z4 (severe damage/structural defects, e.g. cavities, fungal fruiting bodies) and Z5 (instability because of poor anchorage) were included.

\subsection{Sampling the cross-sections for fungal isolations and decay calculations}

The most likely potential position(s) of stem breakage because of decay for each tree was assessed. To accomplish this, a stepwise analysis was used.

Step 1: Before felling, the main external signs of decay on each tree were measured, i.e. height and location of wounds, cracks, cavities, fungal fruiting bodies, other defects. The trees were photographed.

Step 2: After felling, sample discs were cut in cross-sections at the following locations: (i) lower, middle and upper edge of the injuries, (ii) height of external signs of fungal infection (fruiting bodies, sterile outgrowths, cankers), (iii) under and above the crotches of main branches and (iv) upper edge of the decay column(s) in the main stem and branches. Discs were cut from the main stem and main branches up to a maximum height of $8 \mathrm{~m}$, depending on tree size and the main decay column(s) in stem.

Step 3: The height, top/bottom-side, and the cardinal points were marked on the sample discs, and photographed. Decay pattern in each tree was then estimated on the basis of the photographs. 


\subsection{Fungal material and identification}

For fungal isolations, wood pieces cut from the representative decay patterns of each sample disc were enclosed in plastic bags and stored at $-20^{\circ} \mathrm{C}$ until analysed in greater detail. Isolations were made in two ways:

1 Five centimetres long chips were aseptically cut from a freshly exposed surface inside the wood pieces, placed in $1.25 \%$ malt agar in Petri dishes, and incubated for 6 weeks at $15^{\circ} \mathrm{C}$.

2 Pieces of wood $(5 \times 5 \mathrm{~cm})$ with freshly exposed surfaces were cut from the representative decay patterns, incubated at $15^{\circ} \mathrm{C}$, and checked occasionally for a period of 1 year. Pure cultures were isolated from the fungi that grew out of the wood pieces. Samples from 39 trees were treated only using the latter method.

Fungal fruiting bodies were identified using the following texts: JaHN (1979), Breitenbach and Kränzlin (1984), Ryman and Holmåsen (1984) and Ryvarden and GilbeRTSON (1993). Microscopic identification of pure cultures was based on the papers of Nobles (1948), Hallaksela (1977) and Stalpers (1978). Species of Armillaria were identified using mating tests (GUILLAUMin et al. 1991).

Because of the similarities between the fruiting bodies of Ganoderma lipsiense and G. adspersum (e.g. Маттоск 2001), G. lipsiense isolates identity was verified using Internal Transcribed Spacer (ITS) sequence analysis. DNA was isolated as described by VAINIO et al. (1998), amplified using primers ITS1-F and ITS4B (GARDES and BRUNS 1993), sequenced using an automated sequencing device (Li-Cor Global Edition IR $^{2}$ system; Li-Cor Inc., Lincoln, NE, USA) and Therm EXCEL ${ }^{\mathrm{TM}}$ II DNA Sequencing Kit-LC (for $66 \mathrm{~cm}$ gels; Epicentre ${ }^{\circledR}$, Epicentre Biotechnologies, Madison, WI, USA) with ITS1-F and ITS4B primers. DNA fragments were sequenced in both directions, alignment was performed using the CLUSTALW algorithm complemented with a minor manual adjustment and the Neighbor-Joining (NJ) dendrograms were constructed using MEgA software (KumAR et al. 2001). A total of 31 Ganoderma isolates collected from different locations in Europe were compared (Table 1).

Table 1. Ganoderma isolates tested in the study

\begin{tabular}{|lllll|}
\hline Isolate & \multicolumn{1}{c}{ Species } & \multicolumn{1}{c}{ Host } & \multicolumn{1}{c|}{ Location } & Year of isolation \\
\hline Gl FIN 241AA480 & G. lipsiense & Acer platanoides & Helsinki, Finland & 2003 \\
Gl FIN R330 2la & G. lipsiense & Tilia sp. & Helsinki, Finland & 2004 \\
Gl FIN R330 3la & G. lipsiense & Tilia sp. & Helsinki, Finland & 2004 \\
Gl FIN 131R610 & G. lipsiense & Tilia sp. & Helsinki, Finland & 2002 \\
Gl FIN 180KA & G. lipsiense & Acer platanoides & Helsinki, Finland & 2003 \\
Gl FIN 18200 & G. lipsiense & Acer platanoides & Helsinki, Finland & 2001 \\
Gl FIN 187R170 & G. lipsiense & Tilia sp. & Helsinki, Finland & 2003 \\
Gl FIN MPT & G. lipsiense & Tilia sp. & Helsinki, Finland & 1999 \\
Gl FIN 251R90 & G. lipsiense & Tilia sp. & Helsinki, Finland & 2004 \\
Gl FIN 244R40 & G. lipsiense & Tilia sp. & Helsinki, Finland & 2004 \\
Gl EST 15 & G. lipsiense & Acer sp. & Tarto, Estonia & 2004 \\
Gl NOR 53-1143/2 & G. lipsiense & Betula sp. & As, Norway & 1953 \\
Gl NOR 74-67/5 & Cf. G. lipsiense & Betula sp. & As, Norway & 1974 \\
Gl UK 250593.1 & G. lipsiense & Fagus sylvatica & Berkshire, UK & - \\
Gr CH 160999.3 & G. resinaceum & Quercus rubra & Freiburg, Germany & - \\
G sp ITA 35 & Ganoderma sp. & Abies sp. & Arezzo, Italy & 2005 \\
Ga ITA 37 & G. adspersum & Ulmus sp. & Roma, Italy & 2005 \\
Ga ITA 39 & G. adspersum & Laurus nobilis & Roma, Italy & 2005 \\
Ga ITA 42 & G. adspersum & Morus sp. & Roma, Italy & 2005 \\
\hline
\end{tabular}




\subsection{Analysis of the material}

The role of different decay fungi was analysed on the basis of frequency, stage of decay in the affected tree, horizontal extent of decay, crown vitality and by evaluating each species as a potential agent of stem breakage. Frequencies were calculated from fruiting body observations and from pure culture isolations (black sterile knots produced by Inonotus obliquus and rhizomorphs of Armillaria spp. were included in the fruiting body observations). The stage of decay was evaluated at both tree and cross-sectional levels. Three categories were used: discoloured, advanced and hollowed. Crown vitality was assessed as vital or declined. Except for the dead trees, declined trees were grouped in category Z3 (Terho and Hallaksela 2005).

Decayed areas on sample discs were digitized from photographs and stored as point curves with the aid of an in-house software (Finnish Forest Research Institute). Only the decayed area where the wood structure showed visible alterations was accepted: hollow was included, but discoloured wood was not. The area of the decayed regions on the sample discs was calculated automatically by the software. For each sample tree, all potential locations for stem breakage were evaluated on the basis of the cross-sectional photographs.

In addition to the area of decay on cross-section discs, the extension of decay towards the disc margin (cambium) was recorded, as it decreases tree stability by breaking the sound wood cylinder in the stem. 'Cambium-reaching decay' was calculated for each species as a percentage of the cross-sectional discs where the decay had reached the disc margin. Except for Rigidoporus populinus, only discs with successful isolations and identifications were accepted to represent the cambiumreaching decay. Because of difficulties in isolating $R$. populinus, a different criterion was adopted: only those discs where fruiting bodies were observed at the same height from which cross-sectional disc was taken were accepted. Finally, the critical points of tree breakage were estimated on the basis of decay extension and tree architecture, and the role of the different fungi as a potential cause of hazard was evaluated on the basis of occurrence at these points.

\section{Results}

\subsection{Species of fungi}

Thirteen commonly occurring fungal species or genera were identified on the basis of fruiting bodies and isolated pure cultures (Table 2). Pholiota sp. was most frequently detected, isolated from Betula, Tilia and Acer, where it usually occurred together with other fungi. In fact, Pholiota sp. was consistently recorded in the same trees with all other species recorded in the present study (Table 2). In contrast, Hypholoma sp. had an overall low occurrence, was found only in Tilia, and usually was not associated with other species. Mating tests on the Armillaria isolates showed that most were A. cepistipes Velenovský; one isolate was identified as $A$. borealis Marxmüller \& Korhonen. DNA analysis verified that isolates of Ganoderma were the species G. lipsiense. Two clusters were formed in the analysis of the ITS sequences, both of which were supported by $100 \%$ bootstrap values. The first cluster included all Finnish, Norwegian and Estonian isolates of Ganoderma, morphologically as G. lipsiense, and no variation was observed among these isolates (Fig. 1). The second cluster combined G. adspersum isolates from Italy with G. lipsiense isolates from the UK and Italy. Finally, G. resinaceum from Switzerland formed a separate cluster. 


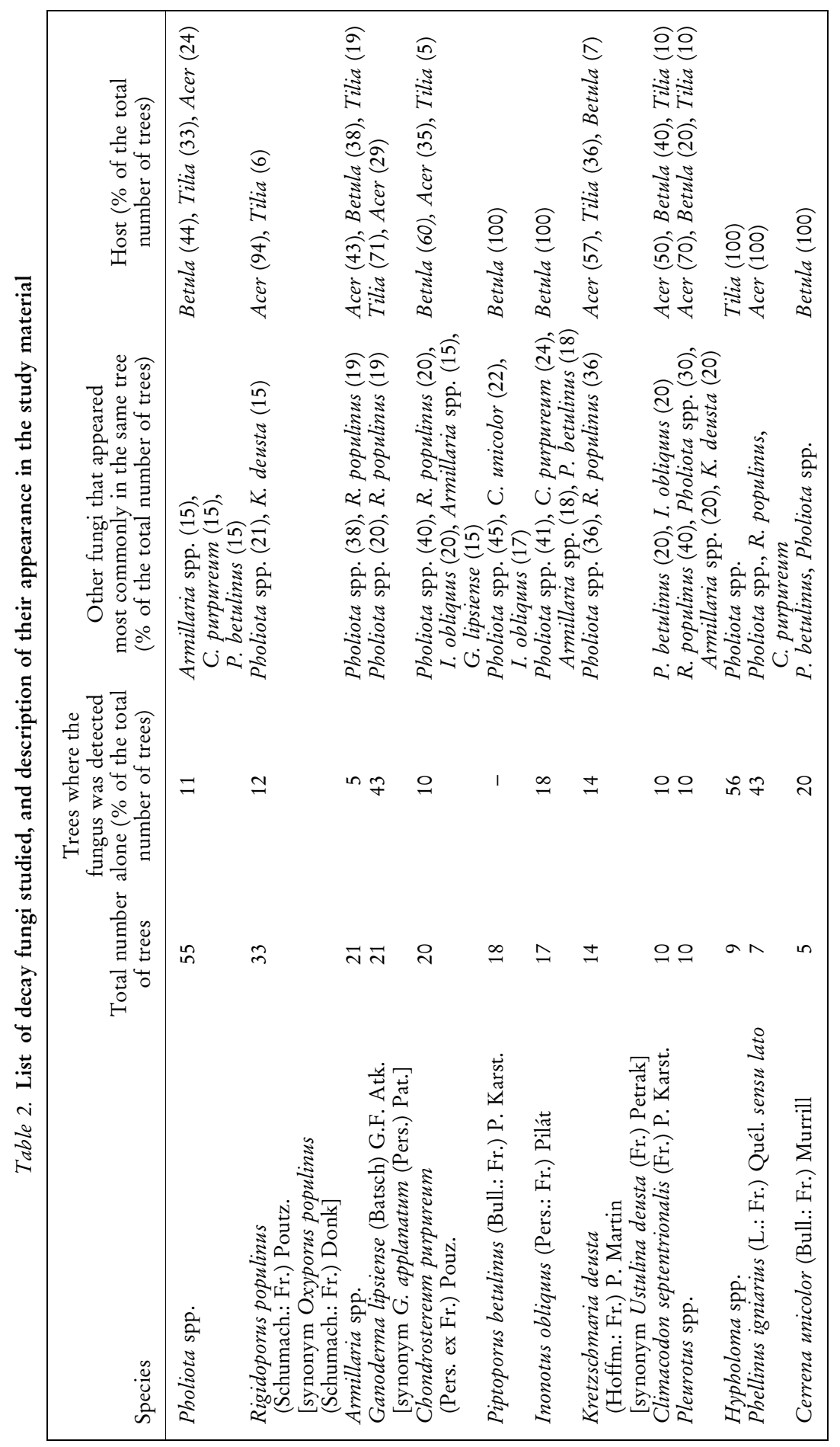




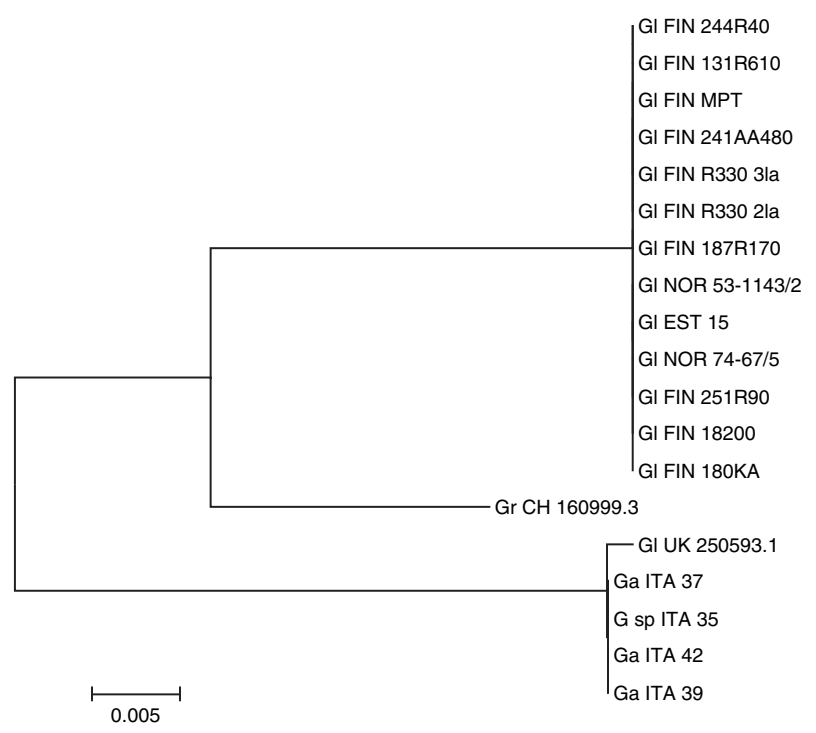

Fig. 1. A Neighbor-Joining tree on the Ganoderma sp. analysed in the study. The first two letters in the isolate codes indicate existing information or morphological identification of the isolate $(\mathrm{Gl}=G$. lipsiense, $\mathrm{Ga}=G$. adspersum and $\mathrm{Gr}=G$. resinaceum), the next two- or three-letter abbreviation indicates the origin of the isolate and the remainder of the code specifies the isolate

\subsection{Diagnostic of decay agents}

All the records of $R$. populinus, G. lipsiense, Phellinus igniarius and Cerrena unicolor could be based on the occurrence and identification of fruiting bodies. In addition, the number and the size of the fruiting bodies indicated the extension of decay. In contrast, an irregular appearance of fruiting bodies decreased the visibility of other common decay fungi. The visibility of these species could be ranked as follows: I. obliquus $>$ Climacodon septentrionalis $>$ Piptoporus betulinus $>$ Kretzschmaria deusta $>$ Armillaria spp. (rhizomorphs) $>$ Chondrostereum purpureum and Pleurotus spp. $>$ Pholiota spp. (Table 3). With most of these species, however, fruiting bodies or their remains were present on the most critical trees, i.e. on trees where the decay caused by the fungus showed widest horizontal spread (Table 4). Hypholoma sp. was never observed as fruiting bodies; it was always isolated from hollowed Tilia trees with no external symptoms of fungal activity (hollowed stems were detected externally by the presence of old decayed pruning wounds).

All the trees colonized by C. unicolor had declining crowns (Table 3). Decline was often visible also in trees infected by $P$. betulinus, I. obliquus and C. purpureum, whereas the occurrence of other species was less frequently associated with crown symptoms (Table 3 ).

\subsection{Decay patterns}

In the whole sample, $57 \%$ of the trees were hollowed, $35 \%$ were in an advanced stage of decay, and $8 \%$ showed only discolouration suggestive of decay.

Hypholoma spp., C. septentrionalis, P. igniarius, Pleurotus spp., Armillaria spp., Pholiota spp., C. unicolor and C. purpureum were mostly (exclusively for Hypholoma spp.) detected 
Table 3. Diagnostics of the fungi studied

\begin{tabular}{|c|c|c|c|}
\hline \multirow[b]{2}{*}{ Species } & Fruiting bodies ${ }^{1}$ observed & Successful isolations & Crown symptoms \\
\hline & \multicolumn{3}{|c|}{$\%$ of the total number of trees per species } \\
\hline Rigidoporus populinus & 100 & 0 & 12 \\
\hline Ganoderma lipsiense & 100 & 71 & 18 \\
\hline Phellinus igniarius & 100 & 86 & 43 \\
\hline Cerrena unicolor & 100 & 60 & 100 \\
\hline Inonotus obliquus & 82 & 100 & 65 \\
\hline Climacodon septentrionalis & 80 & 100 & 10 \\
\hline Piptoporus betulinus & 78 & 61 & 83 \\
\hline Kretzschmaria deusta & 64 & 100 & 21 \\
\hline Armillaria spp. & 33 & 76 & 38 \\
\hline Pleurotus spp. & 20 & 90 & 0 \\
\hline Chondrostereum purpureum & 20 & 90 & 50 \\
\hline Pholiota spp. & 18 & 95 & 33 \\
\hline Hypholoma spp. & 0 & 100 & 0 \\
\hline
\end{tabular}

in hollowed trees. Based on isolations from cross-section samples, C. purpureum, Pleurotus spp. and Pholiota spp. were more primary decay-causing agents than the other species, being also isolated from discoloured parts of the stems (Table 4). Hypholoma spp., C. septentrionalis and Armillaria sp. were, in the majority of cases, isolated in parts of the stem which were already hollowed (Table 4).

In contrast, $K$. deusta, $G$. lipsiense, $R$. populinus and $I$. obliquus were mostly found in trees in an advanced stage of decay. Based on isolations from the cross-section samples and on numbers of trees in which the fungus was detected alone, G. lipsiense and I. obliquus were more primary decay-causing agents than $K$. deusta and $R$. populinus (Tables 2 and 4). Fungi isolated from trees in which decay was merely at discoloured stage were $P$. betulinus, G. lipsiense, Pholiota spp. and C. purpureum. In addition, rhizomorphs of Armillaria spp. were occasionally detected under the bark of such trees (Table 4).

\subsection{Risk of stem breakage}

The widest horizontal decays were caused, in decreasing order, by C. unicolor, I. obliquus, G. lipsiense, $R$. populinus, $P$. igniarius and $K$. deusta. All of these species achieved at maximum of $\geq 70 \%$ decay based on cross-section areas (Table 4 ). In addition, the decay caused by $C$. unicolor and G. lipsiense most often extended to the vascular cambium (Fig. 2). Ganoderma lipsiense, together with $P$. igniarius was also most often isolated from the level in the stem where the horizontal extension of decay was widest, i.e. at the point of highest potential for stem breakage (Fig. 2). This point was below $1 \mathrm{~m}$ in height in $76 \%$ of trees decayed by G. lipsiense (mostly Tilia spp.), increasing the risk of whole trees falling. The location of decay caused by $R$. populinus on Acer spp. was often in fork area of large branches, increasing the risk of branch breakage. In contrast, decay caused by Pholiota spp., Armillaria spp. and Pleurotus spp. seldom reached the cambium and these fungi were rarely isolated from the point of maximum horizontal decay in the stem. Hypholoma spp., C. septentrionalis and $R$. populinus were often present at the point of maximum horizontal decay but the decay never or seldom extended to the cambium (Fig. 2). 


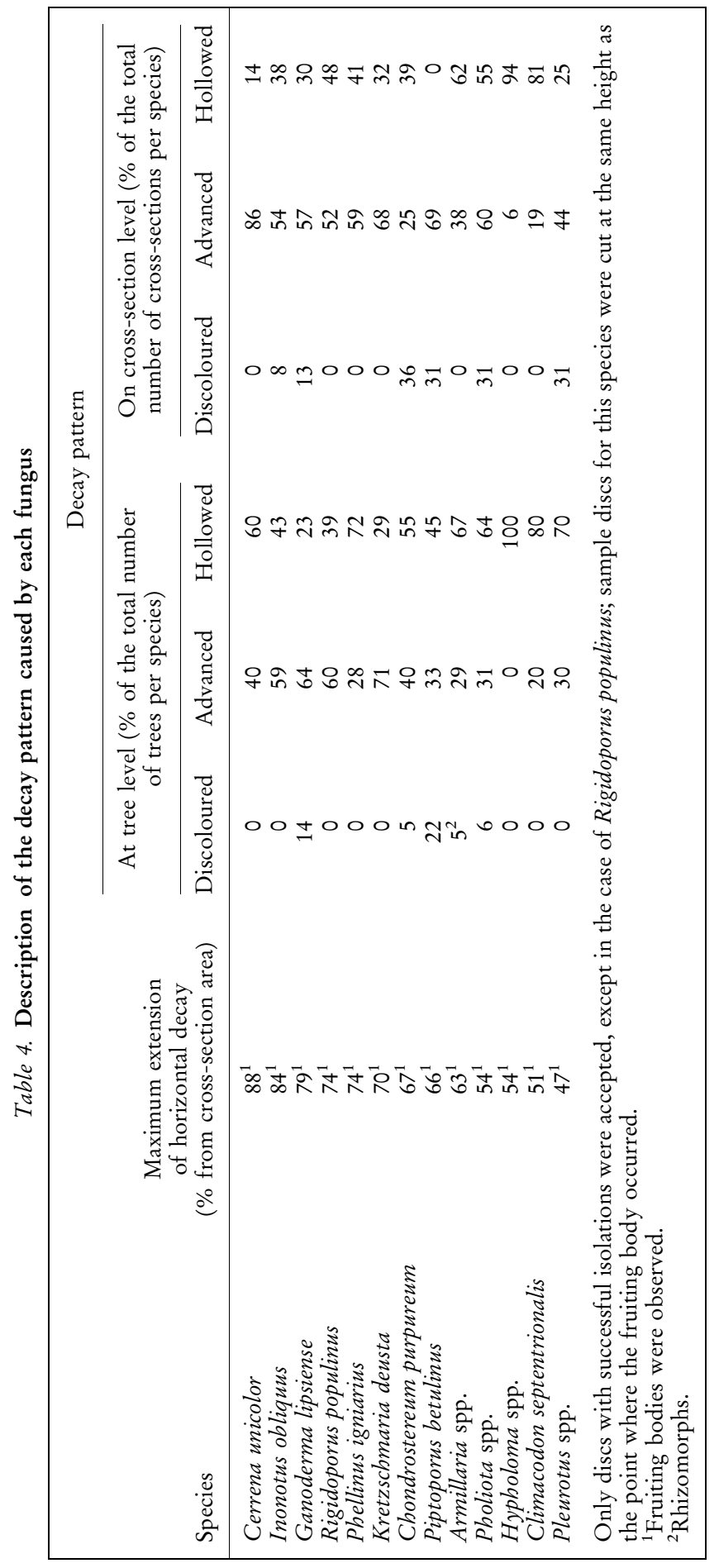




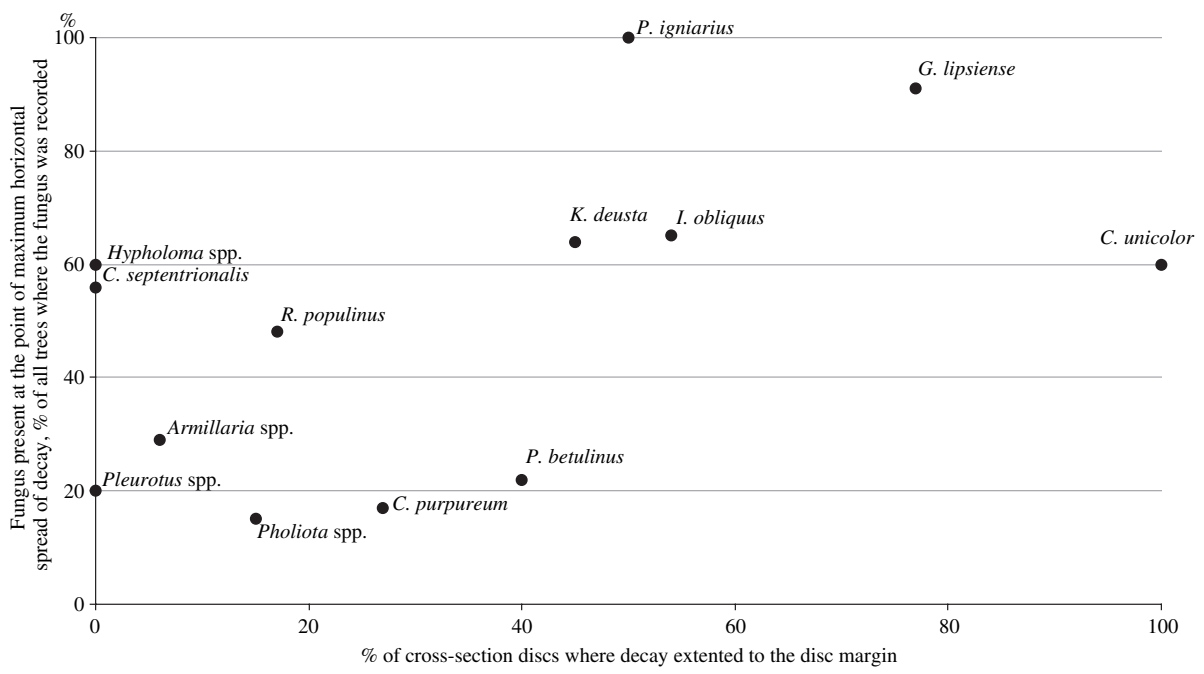

Fig. 2. Potential of the fungi to cause stem breakage

\section{Discussion}

\subsection{Risk of stem breakage hazard}

Thirteen fungal species were commonly found associated with a total of 194 Tilia, Betula and Acer felled as hazardous trees in the Helsinki City area. These species may be ranked differently according to the different risk assessment criteria used: stem breakage hazard, decay process and diagnostic.

The results suggested that C. unicolor, G. lipsiense, I. obliquus, K. deusta and P. igniarius had the greatest potential for causing stem breakage. All of these fungi were able to cause extensive horizontal decay that often extended to the cambium, breaking the sound wood cylinder in the stem and essentially increasing the hazard of breakage. The location of decay caused by $G$. lipsiense and $R$. populinus in the tree architecture was particularly notable. The former often caused extensive decay at the base of the stem, resulting in a high hazard for tree breakage at this point. In Acer trees attacked by $R$. populinus, the location of decay in weak fork formations, rather than wide extension of decay, was usually the reason for breakage hazard.

Compared with the fungi mentioned above, the agarics (Hypholoma, Pholiota, Pleurotus and Armillaria) did not have such a high potential for causing stem breakage. However, some species of Pholiota have been described as root pathogens, and their role as a possible predisposing factor to other species should be noted (Ross 1975; LONSDALE 1999; SCHWARZE et al. 2000). Severely pathogenic species of Armillaria spp. (A. ostoyae and A. mellea) were not found in the trees investigated. Armillaria cepistipes was the dominant species, and $A$. borealis was also recorded. These are the most common Armillaria species found in Finland, and both are mostly saprotrophic but may be weak pathogens of coniferous and broadleaved trees (Korhonen 1978; Roll-Hansen 1985; Prospero et al. 2004).

\subsection{Decay process}

For making felling decisions on trees showing signs of decay, it is important to distinguish between two types of decay fungi: (i) those able to cause progressive horizontal decay and 
(ii) those that are more stable in terms of horizontal spread of decay. According to SMITH (2006) 'a living hollow tree is ultimately an example of successful compartmentalization'. If the critical threshold for the felling decision is not exceeded at the time when the risk assessment is carried out, a worse future prognosis may be given for trees infected by the species in the former group. Among the fungi treated in this study, $K$. deusta, G. lipsiense, $R$. populinus and I. obliquus were in this first group. Most trees infected by these fungi were felled during the active stage of decay. The remaining fungi, especially C. septentrionalis, P. igniarius and the agarics were more pronounced on hollow trees.

Kretzschmaria deusta and G. lipsiense are both regarded as serious pathogens of amenity trees in urban areas (e.g. Schwarze et al. 2000). However, there has been considerable dispute concerning their true pathogenicity. These fungi are reported to occur mainly in those parts of trees previously invaded by other fungi (WILKIns 1934; Ross 1975; Schwarze and Fink 1997), acting as secondary invaders (Phillips and Burdekin 1982; RAYNer and Boddy 1988; Rogers and Ju 1998), but have also been described as primary pathogens (White 1920; Wilkins 1936, 1943). The results obtained in the present work indicated that $G$. lipsiense plays a more primary role in the decay process than $K$. deusta; it could be isolated from discoloured wood, whereas $K$. deusta was not. In addition, G. lipsiense was more frequently the only fungus detected in the tree and was more often isolated from the critical part of the stem.

The role of $R$. populinus as a decay agent could not be comprehensively evaluated because of problems in isolating in pure culture. It is known that $R$. populinus cannot invade intact wood before other organisms first alter it, but $R$. populinus is probably the organism that starts the cell wall degradation process, effectively decomposing both lignin and cellulose, and hence reducing tree stability (SHORTLE et al. 1971; TATTAR et al. 1971; SHIGo 1974).

Inonotus obliquus was also isolated from discoloured wood in the current work. It is able to colonize the wood ahead of successional changes and to degrade the protective barrier zones formed by the tree (BLANCHETTE 1982). The horizontal progression of decay caused by $I$. obliquus is, however, relatively slow and predictable, being widest near the sterile outgrowth of the fungus (Silverborg 1959; Blanchette 1982; Niemelä 2005).

Climacodon septentrionalis and P. igniarius were frequent in trees felled in the hollow stage of decay. Phellinus igniarius was also able to cause extensive horizontal decay, but the results indicated slow horizontal progression of the decay. SEeHann (1979) described $P$. igniarius as a fungus with well-delimited heart rot, which expands outwards slowly. Based on the present results, the same is true with C. septentrionalis; the decay caused did not reach the sapwood in any of the samples measured.

Although the agarics appeared mostly in hollowed trees, Pholiota spp., Pleurotus spp. and Armillaria spp. were isolated also from trees at advanced stage of decay, and Pholiota spp. even from trees at the discoloured stage only. It is known that degradation in living trees is usually not caused by a single species of fungus but rather by a succession of different organisms (e.g. RAYNER and BODDY 1986). In a study on fungal colonization in hardwood stumps, RAYNer (1977) described different phases in the decay process: (i) early colonization (e.g. C. purpureum), (ii) a phase with a variety of species (e.g. large polypores, several agarics) and (iii) dominance of Agaricales. Comparable phases could be detected in fungal colonization of living trees, but defence mechanisms make the process more complicated. In the present study, all isolations of Hypholoma sp. were obtained from hollowed Tilia trees. We suggest that these trees had gone through different phases of decay, leading to hollowing, which then favoured secondary colonization by Hypholoma spp.

A proportion of trees in this study were felled because of crown decline. These trees were grouped in Z3 category and the decay fungi most commonly isolated from them were P. betulinus, C. purpureum, I. obliquus and C. unicolor. All these fungi have been described 
as attacking weakened trees (SEehann 1979; Phillips and Burdekin 1982; ErkKilä and Niemelä 1986; Rayner and Boddy 1988). Decay may be a predisposing factor to decline, but it is often difficult to resolve whether the trees are declining because of decay or vice versa (RAYNER and BODDY 1988). In terms of risk assessment detailed analysis of decay in a tree with serious decline is not necessary, because felling is usually based on the lowered amenity value of the tree.

\subsection{Diagnostics}

Identification of the decay agent is important for reliable assessment of potential risks. In terms of diagnostics, four categories were defined in the present study: (i) species reliably detected based on fruiting bodies (C. unicolor, G. lipsiense, $P$. igniarius and $R$. populinus), (ii) species showing irregular fruiting (I. obliquus, C. septentrionalis, $P$. betulinus, $K$. deusta, C. purpureum, the agarics), (iii) species with a reliably predictable decay column (C. septentrionalis, I. obliquus and P. igniarius) and (iv) species that appeared mostly in trees with lowered vigour (I. obliquus, C. purpureum, C. unicolor and P. betulinus).

Kretzschmaria deusta is reported to be difficult to diagnose (e.g. Schwarze et al. 1995, 2000). In the present study, almost $40 \%$ of records of $K$. deusta were based on isolations in pure culture only. However, the appearance and abundance of $K$. deusta fruiting bodies correlated well with the state of the decay. It is suggested, therefore, that appearance of fruiting bodies of $K$. deusta better indicated a tree that exceeded the critical threshold for felling than appearance of fruiting bodies of species such as G. lipsiense, which fruited on every infected tree, even those only at discolouration stage of decay.

Special attention was drawn for the identification of $G$. lipsiense isolates in this study. Several species of Ganoderma are known as harmful decay agents of urban trees in central Europe, and identification of these species, therefore, is important for correct management of trees (e.g. SCHWARzE et al. 2000). Because of very similar fruiting bodies and differences in ability to break through reaction zones formed in infected trees, identification is especially critical with G. adspersum and G. lipsiense (Schwarze and Baum 2000; MatTock 2001; Schwarze 2001; SChwarze and Ferner 2003). The population study here, based on DNA fingerprinting, supports the field observations that G. lipsiense is the dominant species of Ganoderma in Finland (e.g. Niemelä and Kotiranta 1986; Niemelä 2005). It seems to be genetically uniform in northern Europe, and separate from Ganoderma sp. in the UK, Switzerland and Italy. The results of the present work also suggest that $G$. lipsiense in the UK is conspecific with $G$. adspersum in Italy, but a more through analysis is required to confirm this supposition.

In conclusion, the present study, based on assessment of internal decay, provided a major improvement compared to more traditional inventories of fungi, in terms of risk assessment of stem breakage. Root assessment would also be interesting to consider for a better understanding of decay caused by $G$. lipsiense, $K$. deusta, Armillaria spp. and Pholiota spp. More attention should also be drawn to the reasons for the occurrence of decay; the hazard caused by fungi in urban environments is often a consequence of a human action. Finally, our study points to the complexity of the involvement of fungi in tree decay and to the consequent difficulty in straightforward risk assessment.

\section{Acknowledgements}

The authors would like to thank the staff of the Public Works Department of the City of Helsinki for providing the possibility and technical assistance in collecting the tree material. We would especially like to thank the arborists and other members of city staff, who tirelessly accepted our numerous requests for cross-sectional discs from large stems. Hannu Kalaja, Kerttu Rainio, Sonja Sarsila and Marja-Leena Santanen are also kindly acknowledged for all the technical assistance needed for 
handling the study material. We thank Tuukka Heikura for the software used to digitize and calculate the cross-sectional areas of the sample discs. In addition, Jari Perttunen and Risto Sievänen are thanked for their professional help and co-operation with the computer-based decay analyses, and comments on the manuscript. We would also like to thank Kari Korhonen for characterizing the Armillaria isolates in the study material, and for making valuable and clarifying comments on the manuscript. Märt Hanso, Halvor Solheim, David Ferner and Tiziana Annesi are kindly acknowledged for providing the Ganoderma isolates for the study. John Derome is thanked for the linguistic revision. This study was financed by the Finnish Forest Research Institute, the Ministry of the Environment of Finland, the City of Helsinki, the Rikala Foundation, the Niemi Foundation and the Finnish Society of Forest Science.

\section{References}

Baum, S.; Schwarze, F. W. M. R., 2002: Large-leaved lime (Tilia platyphyllos) has a low ability to compartmentalize decay fungi via reaction zone formation. New Phytol. 154, 481-490.

Blanchette, R. A., 1982: Progressive stages of discoloration and decay associated with the canker-rot fungus, Inonotus obliquus, in birch. Phytopathology 72, 1272-1277.

Blanchette, R. A., 1984: Screening wood decay by white rot fungi for preferential lignin degradation. Appl. Environ. Microbiol. 48, 647-653.

Blanchette, R. A.; Otjen, L.; Effland, M. J.; Eslyn, W. E., 1985: Changes in structural and chemical components of wood delignified by fungi. Wood Sci. Technol. 19, 35-46.

Breitenbach, J.; Kränzlin, F., 1984: Pilze der Schweiz. Band 1. Ascomyceten. Luzern: Verlag Mykologia, 313 pp.

Erkkilä, R.; Niemelä, T., 1986: Polypores in the parks and forests of the City of Helsinki. Karstenia 26, $1-40$.

Gardes, M.; Bruns, T. D., 1993: ITS primers with enhanced specificity for basidiomycetes application on the identification of mycorrhizae and rusts. Mol. Ecol. 2, 113-118.

Guillaumin, J.-J.; Anderson, J. B.; Korhonen, K., 1991: Life cycle, interfertility, and biological species. In: Armillaria Root Disease. Ed. by Shaw C. G. III; Kile, G. A. Washington, DC: USDA Agriculture Handbook No. 691, pp. 10-20.

Hallaksela, A.-M., 1977: Microbial flora isolated from Norway spruce stumps (English summary). Acta Forestalia Fenn. 158, 1-50.

Jahn, H., 1979: Pilze die an Holz wachsen. Herford: Bussesche Verlagshandlung, 268 pp.

Korhonen, K., 1978: Interfertility and clonal size in the Armillariella mellea complex. Karstenia 18, $31-42$.

Kumar, S.; Tamura, K.; Jakobsen, I. B.; NeI, M., 2001: MEGA2: Molecular Evolutionary Genetics Analysis Software. Tempe, Arizona, USA: Arizona Sate University.

Lonsdale, D., 1999: Principles of Tree Hazard Assessment and Management, vol. 7. London: Forestry Commission Handbook, DETR, 388 pp.

Mattheck, C.; Breloer, H., 1994: The Body Language of Trees. A Handbook for Failure Analysis. London: Research for Amenity Trees No. 4. The Stationery Office, 240 pp.

Маттоск, G., 2001: Notes on British Ganoderma species. Emphasising the annual species and G. carnosum. Field Mycol. 2, 60-64.

Niemelä, T., 2005: Polypores, Lignicolous Fungi (English summary). Norrlinia 13, 1-320.

Niemelä, T.; Kotiranta, H., 1986: Polypore survey of Finland: 4. Phaeolus, Fistulina, Ganoderma and Ischnoderma. Karstenia 26, 57-64.

Nobles, M. K., 1948: Studies in forest pathology: VI. Identification of cultures of wood-rotting fungi. Can. J. Res. 26, 281-431.

Pearce, R. B., 1991: Reaction zone relics and the dynamics of fungal spread in the xylem of woody angiosperms. Physiol. Mol. Plant Pathol. 39, 41-55.

Phillips, D. H.; Burdekin, D. A., 1982: Diseases of Forest and Ornamental Trees. Hong Kong: The Macmillan Press Ltd, 435 pp.

Prospero, S.; Holdenrieder, O.; Rigling, D., 2004: Comparison of the virulence of Armillaria cepistipes and Armillaria ostoyae on four Norway spruce provenances. For. Pathol. 34, 1-14.

Rayner, A. D. M., 1977: Fungal colonization of hardwood stumps from natural sources: II. Basdiomycetes. Trans. Br. Mycol. Soc. 69, 303-312.

Rayner, A. D. M.; Boddy, L., 1986: Population structure and the infection biology of wood-decay fungi in living trees. Adv. Plant Pathol. 5, 119-160. 
Rayner, A. D. M.; Boddy, L., 1988: Fungal Decomposition of Wood, its Biology and Ecology. Chichester, UK: John Wiley \& Sons Ltd, 587 pp.

Rogers, J. D.; Ju, Y.-M., 1998: The genus Kretzschmaria. Mycotaxon 68, 345-393.

Roll-Hansen, F., 1985: The Armillaria species in Europe. A literature review. Eur. J. For. Path. 15, 22-31.

Ross, W. D., 1975: Fungi associated with root diseases of aspen in Wyoming. Can. J. Bot. 54, 734-744.

Ryman, S.; Holmåsen, I., 1984: Suomen ja pohjolan sienet (original Svampar en fälthandbok). Porvoo: Werner Söderström, 718 pp.

Ryvarden, L.; Gilbertson, R. L., 1993: European Polypores. Part 1. Oslo, Norway: Fungiflora, 387 pp.

Schwarze, F. W. M. R., 2001: Development and prognosis of decay in the sapwood of living trees. Arboric. J. 25, 321-337.

Schwarze, F. W. M. R.; Baum, S., 2000: Mechanisms of reaction zone penetration by decay fungi in wood of beech (Fagus sylvatica). New Phytol. 146, 129-140.

Schwarze, F. W. M. R.; Ferner, D., 2003: Ganoderma on trees - differentiation of species and studies of invasiveness. Arboric. J. 27, 59-77.

SChWARZE, F. W. M. R.; FINK, S., 1997: Reaction zone penetration and prolonged persistence of xylem rays in London plane wood degraded by the basidiomycete Inonotus hispidus. Mycol. Res. 101, $1207-1214$.

Schwarze, F. W. M. R.; Lonsdale, D.; MatTheck, C., 1995: Detectability of wood decay caused by Ustulina deusta in comparison with other tree-decay fungi. Eur. J. For. Path. 25, 327-341.

Schwarze, F. W. M. R.; Engels, J.; MatTheck, C., 2000: Fungal Strategies of Wood Decay in Trees. Berlin, Heidelberg: Springer-Verlag, 185 pp.

Seehann, G., 1979: Holzzerstörende Pilze an Strassen- und Parkbäumen in Hamburg. Mitt. Dtsch. Denrol. Ges. 71, 193-221.

Shigo, A. L., 1974: Relative abilities of Phialophora melinii, Fomes connatus, and F. igniarius to invade freshly wounded tissues of Acer rubrum. Phytopathology 64, 708-710.

Shigo, A. L., 1979: Tree decay. An expanded concept. USDA Forest Service. Agric. Inf. Bull. 419, $1-73$.

SHORTLE, W. C., 1979: Mechanisms of compartmentalization of decay in living trees. Phytopathology 69, 1147-1151.

Shortle, W. C.; TATtar, T. A.; Rich, A. E., 1971: Effects of some phenolic compounds on the growth of Phialophora melinii and Fomes connatus. Phytopathology 61, 552-555.

Silverborg, S., 1959: Rate of decay in northern hardwoods following artificial inoculation with some common heartrot fungi. For. Sci. 5, 223-228.

SмiтH, K. T., 2006: Compartmentalization today. Arboric. J. 29, 173-184.

STALPERS, J. A., 1978: Identification of wood-inhabiting Aphyllophorales in pure culture. Stud. Mycol. $16,1-248$.

Tattar, T.; Shortle, W. C.; Rich, A. E., 1971: Sequence of microorganisms and changes in constituents associated with discoloration and decay of sugar maples infected with Fomes connatus. Phytopathology 61, 556-558.

Terho, M.; Hallaksela, A.-M., 2005: Potential hazard characteristics of Tilia, Betula, and Acer trees removed in the Helsinki City Area during 2001-2003. Urban For. Urban Green. 3, 113-120.

Vainio, E.; Korhonen, K.; Hantula, J., 1998: Genetic variation in Phlebiopsis gigantea as detected with random amplified microsatellite (RAMS) markers. Mycol. Res. 102, 187-192.

White, J. H., 1920: On the biology of Fomes applanatus (Pers.) Wallr. Trans. Roy. Can. Inst. 12, 133174.

WiLkins, W. H., 1934: Studies in the genus Ustulina - with special reference to parasitism: I. Introduction, survey of previous literature and host index. Trans. Br. Mycol. Soc. 18, 320-346.

WILKINS, W. H., 1936: Studies in the genus Ustulina - with special reference to parasitism: II. A disease of the common lime (Tilia vulgaris Hayne) caused by Ustulina. Trans. Br. Mycol. Soc. 20, 133-156.

WiLkins, W. H., 1943: Studies in the genus Ustulina - with special reference to parasitism: VI. A brief account of heart rot of beech (Fagus sylvatica L.) caused by Ustulina. Trans. Br. Mycol. Soc. 26, 169-170. 